\title{
High-altitude salt lake elevation changes and glacial ablation in Central Tibet, 2000-2010
}

\author{
MENG Kai ${ }^{1,2 *}$, SHI XuHua ${ }^{3}$, WANG Erchie ${ }^{1} \&$ LIU Feng ${ }^{1,2}$ \\ ${ }^{1}$ State Key Laboratory of Lithospheric Evolution, Institute of Geology and Geophysics, Chinese Academy of Sciences, Beijing 100029, China; \\ ${ }^{2}$ Department of Geosciences, Graduate University of Chinese Academy of Sciences, Beijing 100049, China; \\ ${ }^{3}$ Department of Geosciences, The Pennsylvania State University, PA 16802, USA
}

Received August 16, 2011; accepted October 8, 2011; published online November 19, 2011

\begin{abstract}
This research quantifies lake level variations in the Siling Co, Co'e and Bangor Co salt lakes in Central Tibet from 1976 to 2010 , and most notably for the 2000-2010 periods. In particular, the effects of different water replenishment modes on the lakes have been analyzed. Here we have provided new evidences for climate warming and accelerated glacial ablation on the Central Tibetan Plateau from 2000 to 2010. Based on fieldwork involving Differential Global Positioning System (DGPS) surveying and Remote Sensing (RS) interpretations of the lake area, we have drawn the following conclusions. (1) From 1976 to 2010, the process of lake level variation in Siling Co can be divided into two stages. From 1976 to 2000, the lake level rose $4.3 \mathrm{~m}$ in a steady fashion (from 4530 to $4534.3 \mathrm{~m}$ ); the rise rate was $0.18 \mathrm{~m} / \mathrm{a}$. From 2000 to 2010, the lake level rapidly rose $8.2 \mathrm{~m}$ (from 4534.3 to 4542.5 $\mathrm{m}$ ), with a dramatically higher rise rate of $0.82 \mathrm{~m} / \mathrm{a}$. Compared with the rapidly increasing lake level of Siling Co from 2000 to 2010, the fluctuations observed at Co'e and Bangor Co were smooth and inconspicuous. (2) From 1976 to 2009, the lake area of Siling Co experienced a steady-rapid-steady expansion pattern. The lake area of Siling Co increased $656.64 \mathrm{~km}^{2}$ in the 34 years to 2010, a proportional growth of $39.4 \%$. This was particularly significant in the 2000-2010 period, when the lake area of Siling Co increased by $549.77 \mathrm{~km}^{2}$, a proportional growth of $30.6 \%$. (3) According to correlation analysis, the rise in regional temperatures, which has led to the ablation of glaciers, is the main reason for the rapid rise in Siling Co lake levels in the 10 years to 2010. During this period, Siling Co rose approximately $8 \mathrm{~m}$ as the direct result of glacial melting. An increase in precipitation in the Siling Co catchment area is the secondary factor. This contrasts with Bangor Co, where the dominant factor in lake level change is the long-term increase in precipitation; here, the increasing temperature is the secondary factor.
\end{abstract}

Siling Co, Co'e, Bangor Co, high-altitude salt lake, lake level increase, glacier ablation, climate change, correlation analysis

Citation: $\quad$ Meng K, Shi X H, Wang E, et al. High-altitude salt lake elevation changes and glacial ablation in Central Tibet, 2000-2010. Chin Sci Bull, 2012, 57: 525-534, doi: 10.1007/s11434-011-4849-5

In recent years, climate change has become one of the most topical issues in earth sciences because of its relevance to the survival and development of human society [1]. Many discussions have focused on glaciers, marine environments and inland lakes, which are very sensitive to the climate change [2]. As the third pole of the earth, Tibet, and especially the inland lakes distributed there, have been a focus of much earth science research [3-9]. Tibet is particularly relevant for such studies because of its many unique features including the sparse population and the well-pre-

*Corresponding author (email: Michael.meng@mail.igcas.ac.cn) served natural environment. The inland lakes of Tibet have not been seriously influenced by human activities, but are more sensitive to regional climate change. Therefore, these lakes (such as Nam Co [4,6], Siling Co [3,10], Lungmu Co and Sumxi Co $[11,12])$ have become the most sensitive indicators to climate change on the Tibetan Plateau. Previous significant and meaningful research has concentrated on the relationship between changes in the inland lakes with regional climate change. However, most scholars have paid more attention to changes in individual lakes, rather than contrasting changes of various lakes with similar microclimatic conditions. Obviously, this kind of contrastive 
research is critical for understand the response mechanisms of various meteorological parameters on lake properties. Salt lakes Siling Co, Co'e and Bangor Co lie within $10 \mathrm{~km}$ of each other (Figure 1), and have similar climatic conditions. They provide a convenient location for analyzing change in similar lakes. In particular, the internal links between lake change and modes of replenishment can be studied.

\section{Background}

The Tibetan Plateau is the highest and largest inland lake area on earth. The total area of the modern lakes there is about $37000 \mathrm{~km}^{2}$, which accounts for $52 \%$ of the total area of lakes in China [13]. There are more than 600 lakes with an area larger than $1 \mathrm{~km}^{2}$ in Tibet [14]. Northern Tibet is surrounded by extensive mountain ranges such as
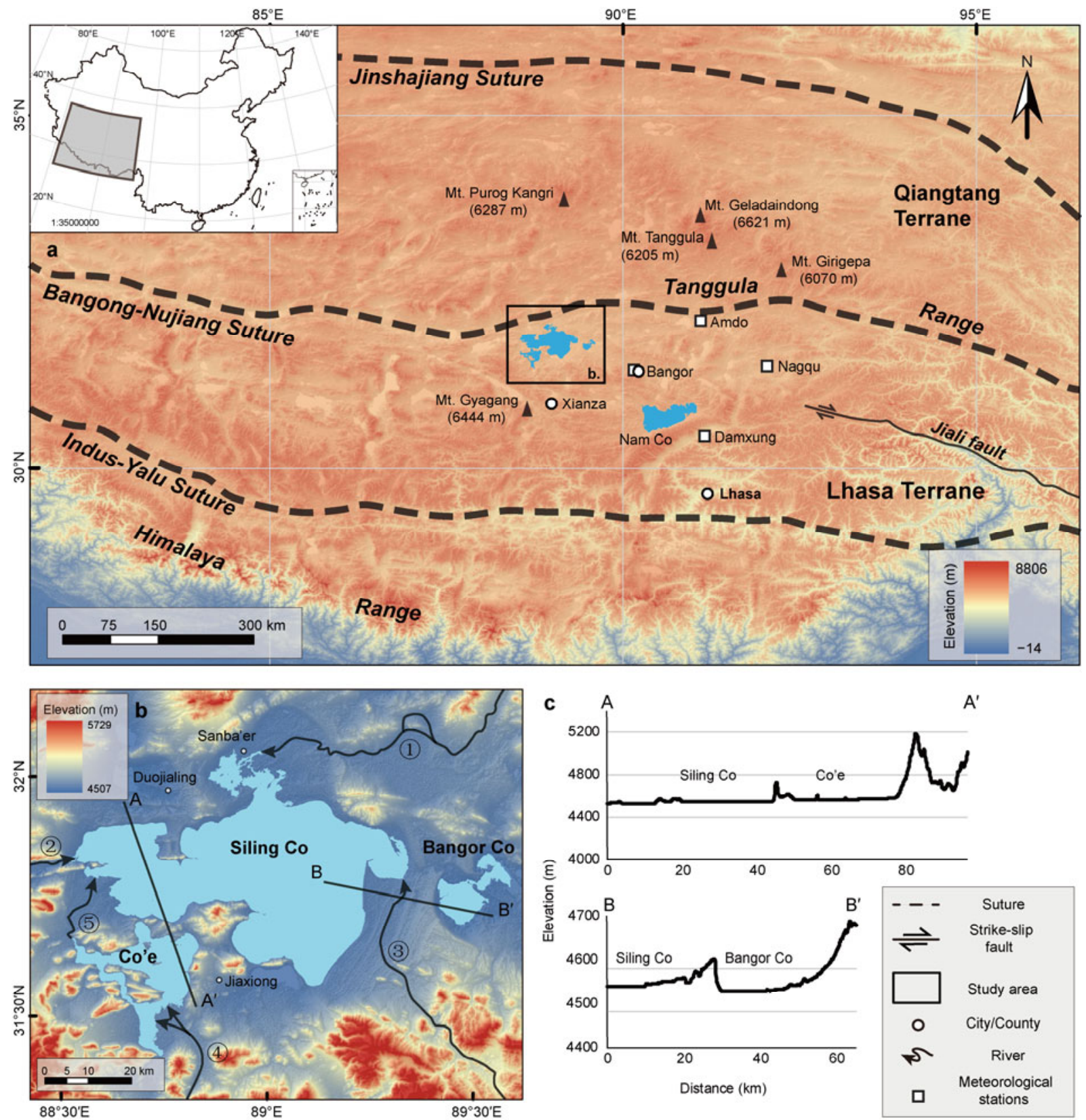

Figure 1 a, Tectonic and topographic map of Central Tibet. The grey box in the index map outlines the geographic location of the main map. b, Topography and major rivers around Siling Co. (1) Zhajiazangbu River, (2) Zhagenzangbu River, (3) Boquzangbu River, (4) Daergewazangbu River, (5) Alizangbu River. c, Topographical profile map. A-A' profile is across Siling Co and Co'e and B-B' profile is across Siling Co and Bangor Co. The DEM data are downloaded from the website (http://srtm.csi.cgiar.org). 
Nyainqêntanglha, Tanggula, and Kunlun [5]. The glaciated ridges of these mountains exceed $5500 \mathrm{~m}$. There are 36793 modern glaciers mapped on the Tibetan Plateau, with a total area of $49874 \mathrm{~km}^{2}$, and an ice volume of circa $4560 \mathrm{~km}^{3}$ [15].

Siling Co is $80 \mathrm{~km}$ away from Bangor, Nagqu. It is the lake boundary of Bangor, Xianza and the Shuanghu Special Administrative Region (Figure 1a). Siling Co recently has overtaken Nam Co as the largest lake in Tibet [10]. At the end of October 2010, the lake elevation of Siling Co was $4542.5 \mathrm{~m}$ and the lake area was $2323.6 \mathrm{~km}^{2}$. Co'e is $1 \mathrm{~km}$ south of Siling Co. Its elevation is $4562.8 \mathrm{~m}$ and its lake area is $274.1 \mathrm{~km}^{2}$. Bangor Co is $8 \mathrm{~km}$ east of Siling Co. Its elevation is $4522.5 \mathrm{~m}$ and its lake area is $130.6 \mathrm{~km}^{2}$. The latter two lakes are actually lagoons of Siling Co, which are separated from Siling Co by sand barriers.

The drainage area of Siling Co covers $45530 \mathrm{~km}^{2}$, which makes it the largest inland lake drainage system in Tibet [16]. As Figure 1b shows, Siling Co has three perennial replenishment rivers: the Zhajiazangbu River flows into Siling Co at Sanba'er from the north, the Boquzangbu River and the Zhagenzangbu River flow into the lake at Gariqiu from the east and at Yagula from the west, respectively. The Zhajiazangbu River is $409 \mathrm{~km}$ long and it is the longest inland river in Tibet. It originates from Mt. Tanggula (6205 $\mathrm{m})$, Mt. Geladaindong $(6621 \mathrm{~m})$ and Mt. Girigepa $(6070 \mathrm{~m})$ in Northern Tibetan. The Zhagenzangbu River originates from Mt. Gyagang $(6444 \mathrm{~m})$, which is close to Xianza County. The Boquzangbu River originates from Mt. Baburi (5654 m) [10]. The main supplementary rivers of Co'e are the Daergewazangbu and Xiagangzangbu rivers, which both flow into Co'e from the southeast. Neither originates from glacial mountains, but some small glaciers may be distributed within their drainage areas. A tributary of Bangor Co is the Kawazangbu River. It originates from Mt. Langqin $(5506 \mathrm{~m})$ in the south, and has no glacial input [5]. To summarize, the supplementary water of Siling Co is glacial melt water. However, Co'e and Bangor Co mainly depend on atmospheric precipitation.

\section{Methods and data sources}

\subsection{Methods}

By comparing satellite images from 1976-2009, changes in Siling Co, Co'e and Bangor Co have been identified. Lake elevations in 2010 can be obtained by DGPS measurements. By analyzing changes in lake area and DEM images, we obtained a record of the lake elevations in different years. Finally, by comparing the meteorological data of neighboring regions, we have interpreted specific reasons for various effects on the three lakes.

ENVI, ArcGIS, and ERDAS were used to process RS images, which have been processed by radiation correction. We used the geometric correction and ortho-rectification functions in ENVI to modify the images, which limited positional errors to within one pixel. All coordinate data are in the WGS-1984-UTM projection. The region of the lakes was extracted by ArcGIS and ERDAS software using the following steps: (1) The unsupervised classification function in ERDAS was used to classify the images based on the contrasting infrared spectrum absorption features of water bodies and other objects. In this step, image was divided into two categories of vector data. (2) The data transfer function in ERDAS was used to transfer the vector data into raster data. Then, visual investigation was used to amend the boundary of the lakes in ArcGIS to limit the calibration error to within one pixel. (3) The lake area was calculated based on the number of pixels and the real area of an individual pixel.

Measurements of DGPS lake level elevations followed the steps shown in Figure 2. (1) A stable reference point was selected as a GPS base station, which was accurately located using a long-period record over several days. The distance between elevation measurement points in the field and the base station was less than $20 \mathrm{~km}$. (2) A known terrain triangulation point in the Siling Co region was compared to the DGPS measurement results to check the error between the actual elevation of the triangulated location and the actual correction elevation. (3) The elevations of lakes were then measured and corrected. The accuracy of DGPS for elevation measurement here is $\pm 0.1 \mathrm{~m}$.

Because of the scarcity of meteorological stations in Tibet, we can only use limited data from four meteorological stations around Siling Co (i.e. the Bangor, Amdo, Nagqu, and Damxung stations; meteorological data from Xianza station from 1990 to 2000 were missed) for statistical analysis. Annual precipitation, percentage of annual precipitation anomaly, annual average temperature and annual average temperature anomaly were calculated. In addition, 2and 5-year moving average values were computed. Finally, we did some correlation analysis using the lake area and meteorological statistical data to find the main factors that dominated lake changes in the 40 years to 2010 .

\subsection{Data sources}

The data used in this paper come from two sources: (1) RS data downloaded from the U. S. Geological Survey web site (http://glovis.usgs.gov), as shown in the following table (Table 1); and (2) regional meteorological data from 19762007 that were collected from meteorological stations in Bangor, Nagqu, Amdo, and Damxung. Glacial lake fluctuations are likely to be affected by both the hot season and the rainy season over the course of a year, whereas changes in the lagoons are likely only to mainly relate to the rainy season. The hot season and the rainy season in Tibet usually last from June to September. The lake levels generally attain a maximum elevation in September or October. For this work, we measured lake elevations during September and 


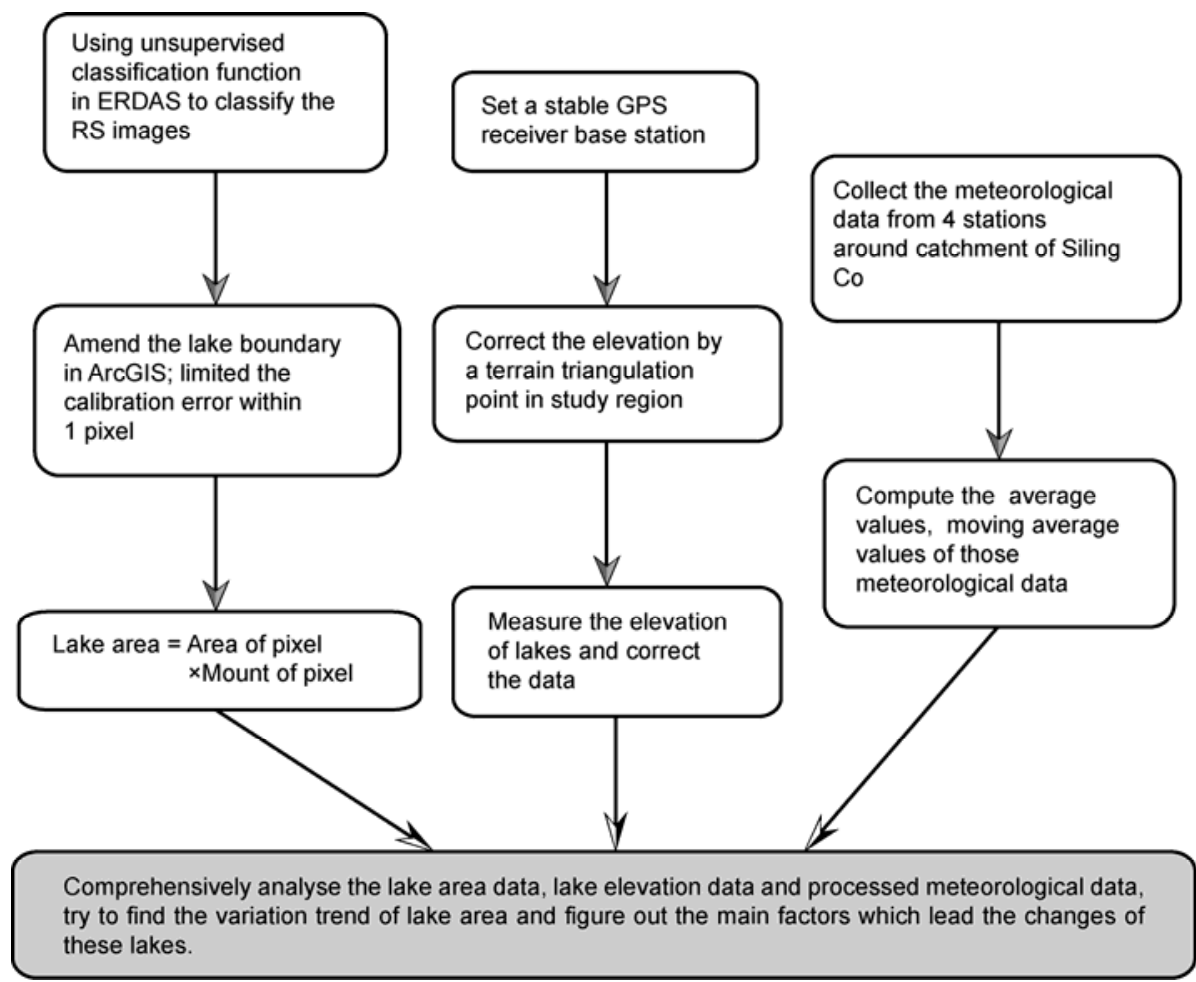

Figure 2 Flow chart of research methods.

Table 1 RS data (LandSAT) summary

\begin{tabular}{ccccc}
\hline Acquisition date & Dataset & Resolution $(\mathrm{m})$ & Path/Raw & Data type \\
\hline $1976-10-08$ & MSS & 79 & $150 / 38$ & GeoTIFF \\
$1990-06-30$ & TM & 30 & $139 / 38$ & GeoTIFF \\
$1999-09-19$ & ETM+ & 30 & $139 / 38$ & GeoTIFF \\
$2002-10-29$ & TM & 30 & $139 / 38$ & GeoTIFF \\
$2007-10-03$ & TM & 30 & $139 / 38$ & GeoTIFF \\
$2009-11-25$ & TM & 30 & $139 / 38$ & GeoTIFF \\
\hline
\end{tabular}

October 2010. To reduce the errors caused by seasonal changes, we tried to select the available images that were acquired in September or October.

\section{Results}

\subsection{Lake area changes}

As shown in Figures 3 and 4, changes happen at different rates and over different spans of time at Siling Co, Co'e and Bangor Co. From 1976 to 2009, the area of Siling Co grew consistently, but its growth rate changed over time. Over the same time period, the area of Co'e remained stable with the exception of some slight fluctuations in a few particular years. The area of Bangor Co grew consistently, but the growth increment was relatively small.

In Figure 4, the changes in the level and extent of Siling Co can be divided into three stages over the period from 1976 to 2009. During 1976-1999 and 2007-2009 the lake experienced stable growth, but in the intervening period from 1999-2007 the growth was rapid. The area of Siling Co was $1666.96 \mathrm{~km}^{2}$ in 1976 and $1722.39 \mathrm{~km}^{2}$ in 1990 . By the end of 1999, the lake area had increased to $1798.95 \mathrm{~km}^{2}$. In comparison, the two consecutive phases experienced a growth in area of $55.43 \mathrm{~km}^{2}(3.32 \%)$ and $76.56 \mathrm{~km}^{2}$ $(4.44 \%)$, respectively. This corresponds to annual growth rates of 3.96 and $8.51 \mathrm{~km}^{2} / \mathrm{a}$. From 1999 to 2007, the lake area significantly increased by $488.68 \mathrm{~km}^{2}$ (from 1798.95 to $2287.63 \mathrm{~km}^{2}$ ), corresponding to a proportional growth of $27.16 \%$ at an annual growth rate of $61.09 \mathrm{~km}^{2} / \mathrm{a}$. After 2007, the growth rate of Siling Co stabilized. By the end of November 2009 , the lake area had increased by only $35.97 \mathrm{~km}^{2}$ compared with 2007, an annual growth rate of $18 \mathrm{~km}^{2} / \mathrm{a}$. To summarize, the area of Siling Co has increased by 656.64 $\mathrm{km}^{2}(39.39 \%)$ in the 10 years to 2009 . The increase in the area of Siling Co from 1999 to 2009 was about four times that of the increment from 1976 to 1999 . Based on the RS images, we found that as the water level continued to rise, Siling Co became connected to Yagedong Co, close to the Changdugang sand barrier, between 2003 and 2005. In the subsequent period, the lake gradually expanded to the western coast of Yagedong Co.

The lake area of Co'e, in contrast, has remained relatively stable, although slight fluctuations have been noted. Compared with the previous time phase, the areal increment of Co'e was $-0.11 \mathrm{~km}^{2}$ in $1990,4.24 \mathrm{~km}^{2}$ in $1999,1.13 \mathrm{~km}^{2}$ in $2002,-3.98 \mathrm{~km}^{2}$ in 2007 and $4.83 \mathrm{~km}^{2}$ in 2009 . The major growth region for Co'e has been in the village of Qilin 


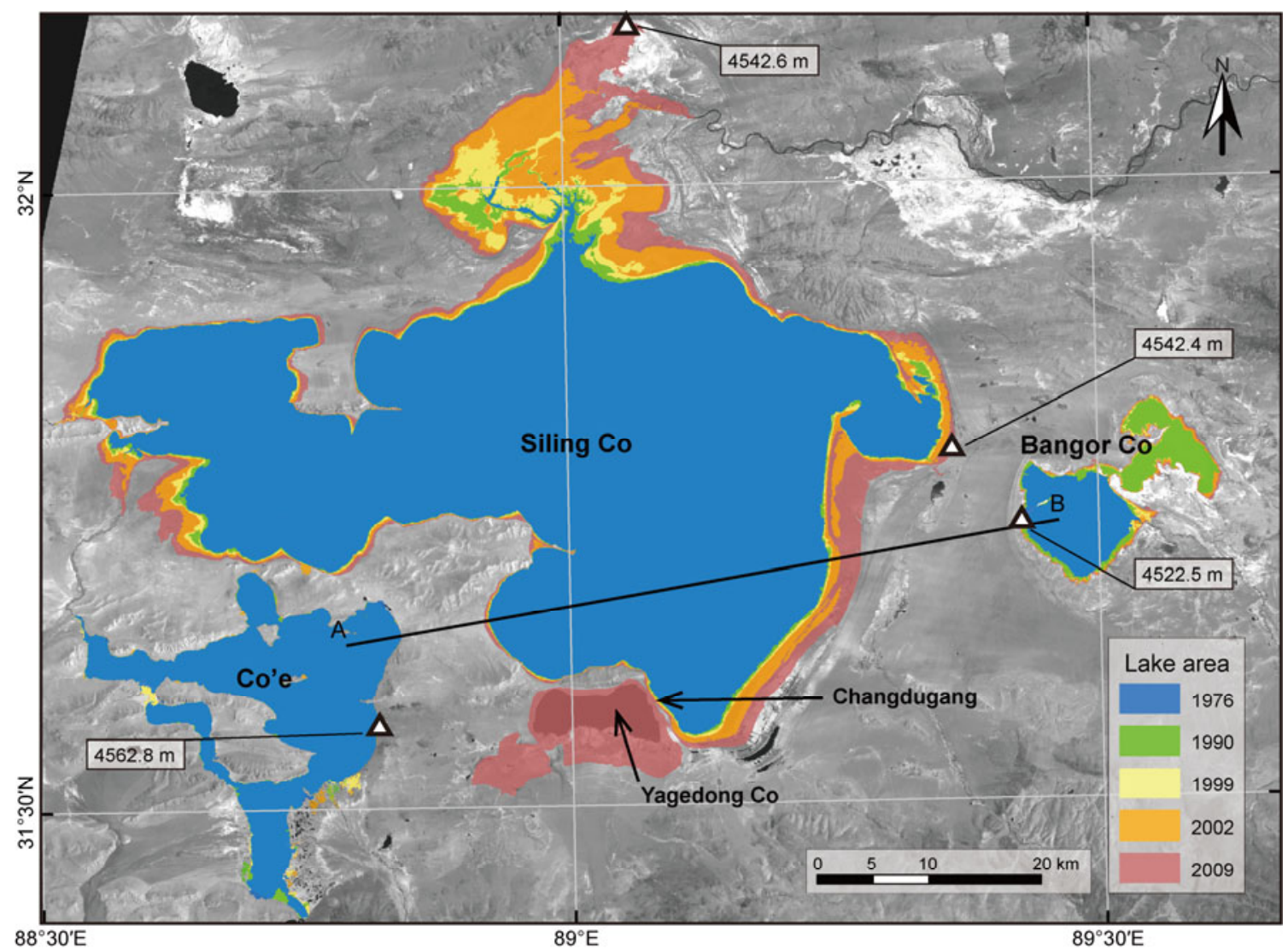

Figure 3 Lake area variation for 1976-2009 and DGPS measurement data (triangles) in 2010. Line A-B projects the topographic profile across those lakes (Figure 5). The background image (1990-06-30 LandSAT TM band 4) was downloaded from http://glovis.usgs.gov.

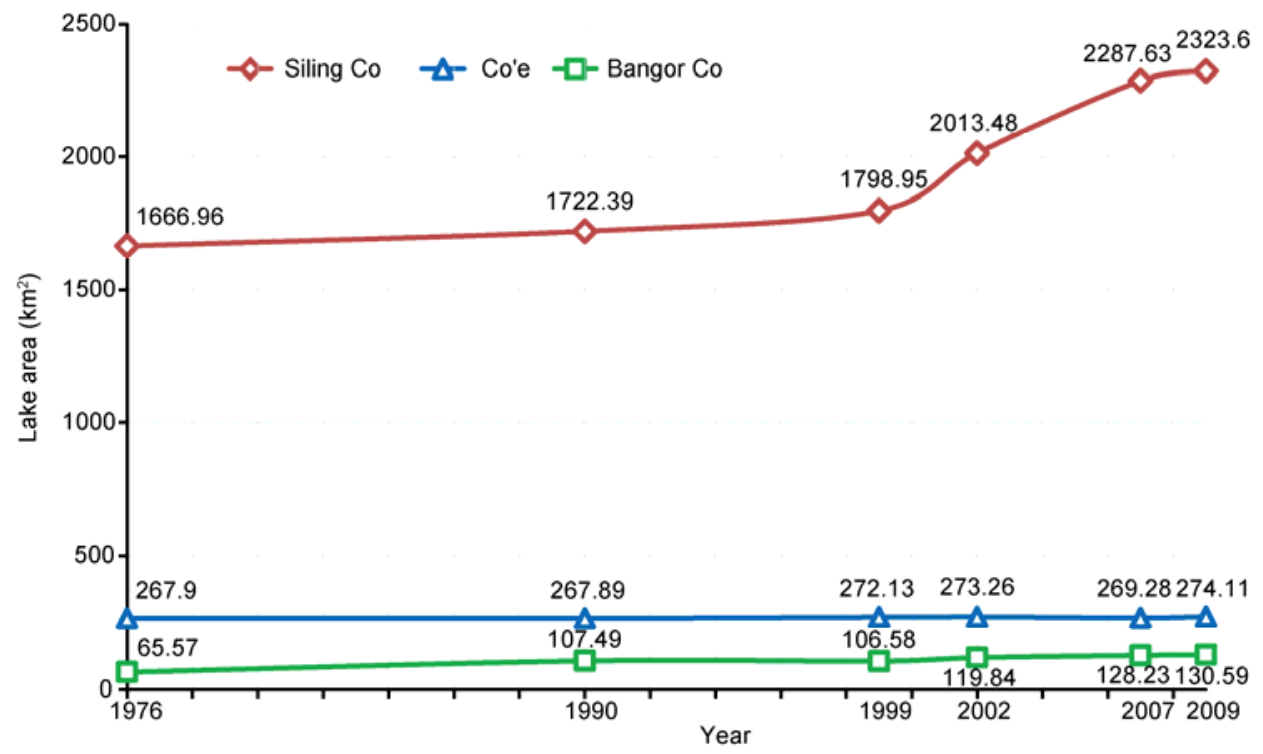

Figure 4 Comparison of lake area variation for Siling Co, Co'e and Bangor Co during 1976-2009.

on its southeastern shore. Near Qilin, the main supplementary river, the Daergewazangbu River and the Xiagangzangbu River flow in to Co'e (Figures $1 \mathrm{~b}$ and 3), forming an alluvial fan with an area of about $30 \mathrm{~km}^{2}$. As a result, this region is more sensitive to lake level rise, because of its moderate topography.

The lake area of Bangor Co increased overall from 1976 to 2009, but with slight fluctuations in some years. Compared with the previous time phase, the areal increment of Bangor Co was $41.92 \mathrm{~km}^{2}$ in $1990,-0.91 \mathrm{~km}^{2}$ in 1999 , 
$13.26 \mathrm{~km}^{2}$ in 2002, $8.39 \mathrm{~km}^{2}$ in 2007, and $2.36 \mathrm{~km}^{2}$ in 2009 . By the end of 2009, the lake area of Bangor Co had increased by $92.62 \%$ in comparison to 1976 .

\subsection{Lake level changes}

The topographical profile crossing the three lakes examined here can be compared to a ladder that gradually decreases from west to east (Figure 5). This figure identifies the elevation of the lake as observed from a 1976 topographic map, 2000 SRTM data and 2010 data measured with DGPS (this fieldwork). As shown in Table 2, the lake level of Siling Co rose $4.3 \mathrm{~m}$ from 1976 to 2000 , with an average rate of increase of $0.18 \mathrm{~m} / \mathrm{a}$. From 2000 to 2010 , the lake level rose $8.2 \mathrm{~m}$, with an average increase rate of $0.82 \mathrm{~m} / \mathrm{a}$. This result is consistent with other remote sensing studies $(0.8 \mathrm{~m} / \mathrm{a})$ $[17,18]$. Although the DEM has some errors, the lake elevation changes matched well with the changes in lake area before and after 2000 (Figures 4 and 5, and Table 2), and this results further supports the accuracy of the elevation changes. Compared over two periods, Siling Co had the greatest rate of lake level increase. However, the rate of elevation increase for Bangor Co has not resulted in significant changes over the two periods. The rate of elevation increase for Co'e grew to $0.45 \mathrm{~m} / \mathrm{a}$ from $0.1 \mathrm{~m} / \mathrm{a}$.

\subsection{Meteorological data}

A comprehensive analysis of annual precipitation anomaly data from meteorological stations in the region has found that the annual precipitation in the Siling Co area in the 1970s was significantly less than the historical average. This "dry period" lasted about 10 years. From 1980 to the mid-1990s, the annual precipitation in the region returned to historical levels. From 1997 to 2007, however, rainfall showed an overall increase, with a maximum annual precipitation $(507.3 \mathrm{~mm})$ occurring in 2003. During that period, the annual precipitation remained about $10 \%$ higher than normal (Figure 6). These results accentuate the overall increase in magnitude and duration of precipitation over the 40 years to 2009 .

In addition, by analyzing the annual average temperature anomaly data, we have found that the annual average temperatures in the eastern part of Tibet decreased significantly from the late 1970 s to the mid-1980s. This "cooling process" can be matched to the "dry period" which was mentioned above. However, from the late 1990s, there has been a "warming process" that has lasted more than 10 years (Figure 7). The growth rate of annual average temperatures exceeds approximately $0.3^{\circ} \mathrm{C}$, which is consistent with previous findings $[15,19-21]$.

\section{Discussion}

\subsection{Main factors of lake change}

According to correlation analysis, we have found that changes in the area of Siling Co are significantly related to long-term temperature changes (Table 3 ), with a correlation coefficient of about 0.9 (Figure $8 \mathrm{a}, \mathrm{b}$ ). This indicates that the increase in the regional long-term temperature is the main factor contributing to the increased expanse and elevation of

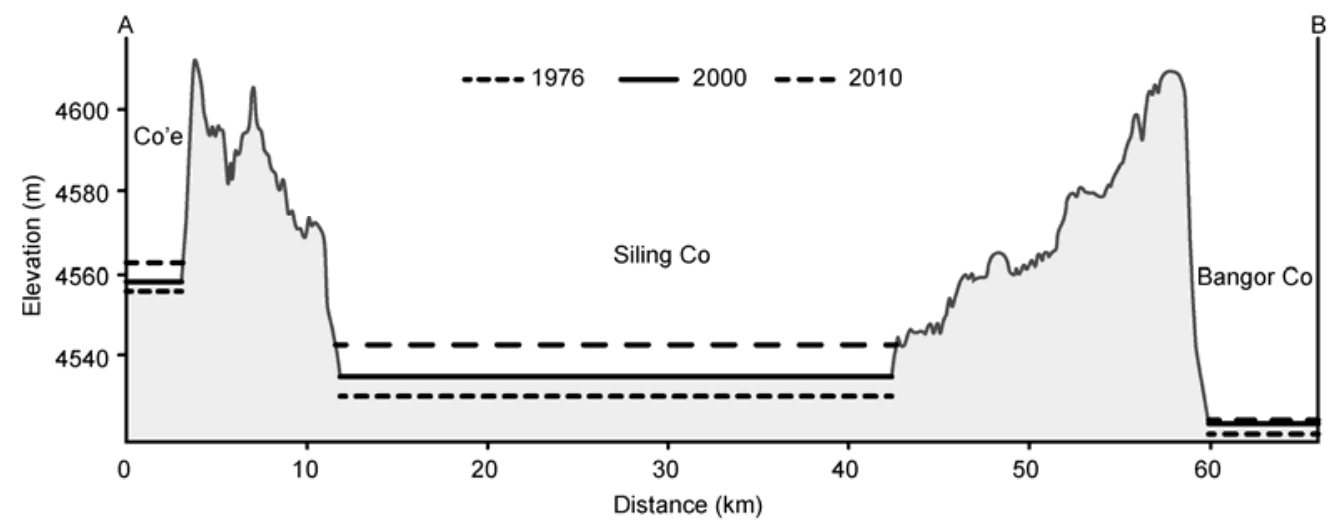

Figure 5 Lake level elevations of Siling Co, Co'e and Bangor Co in 1976, 2000 and 2010. The location of A-B profile line has been shown in Figure 3. The vertical axis has been exaggerated in this schema.

Table 2 Lake level of Siling Co, Co'e and Bangor Co in 1976, 2000 and 2010

\begin{tabular}{|c|c|c|c|c|c|c|c|}
\hline & $\begin{array}{c}\text { Lake level } \\
\text { in } 1976(\mathrm{~m})\end{array}$ & $\begin{array}{l}\text { Lake level } \\
\text { in } 2000(\mathrm{~m})\end{array}$ & $\begin{array}{l}\text { Lake level } \\
\text { in } 2010(\mathrm{~m})\end{array}$ & $\begin{array}{c}\text { Increment in } \\
1976-2000(\mathrm{~m})\end{array}$ & $\begin{array}{c}\text { Growth rate in } \\
1976-2000(\mathrm{~m} / \mathrm{a})\end{array}$ & $\begin{array}{c}\text { Increment in } \\
2000-2010(\mathrm{~m})\end{array}$ & $\begin{array}{c}\text { Growth rate in } \\
2000-2010(\mathrm{~m} / \mathrm{a})\end{array}$ \\
\hline Siling Co & 4530 & 4534.3 & 4542.5 & $\uparrow 4.3$ & 0.18 & $\uparrow 8.2$ & 0.82 \\
\hline Co'e & 4556 & 4558.3 & 4562.8 & $\uparrow 2.3$ & 0.1 & $\uparrow 4.5$ & 0.45 \\
\hline Bangor Co & 4520.6 & 4522.3 & 4522.5 & $\uparrow 1.7$ & 0.07 & $\uparrow 0.2$ & 0.02 \\
\hline
\end{tabular}




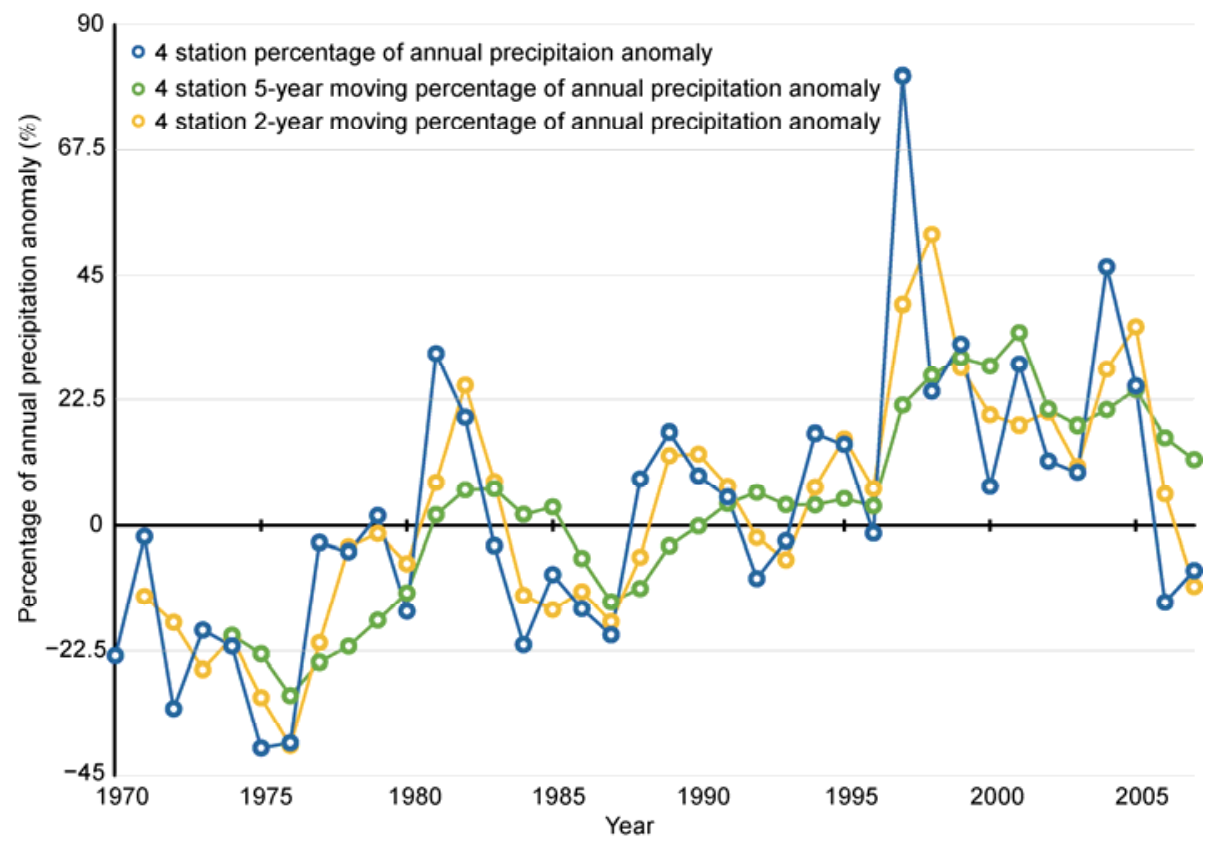

Figure 6 Percentage of precipitation anomaly statistics.

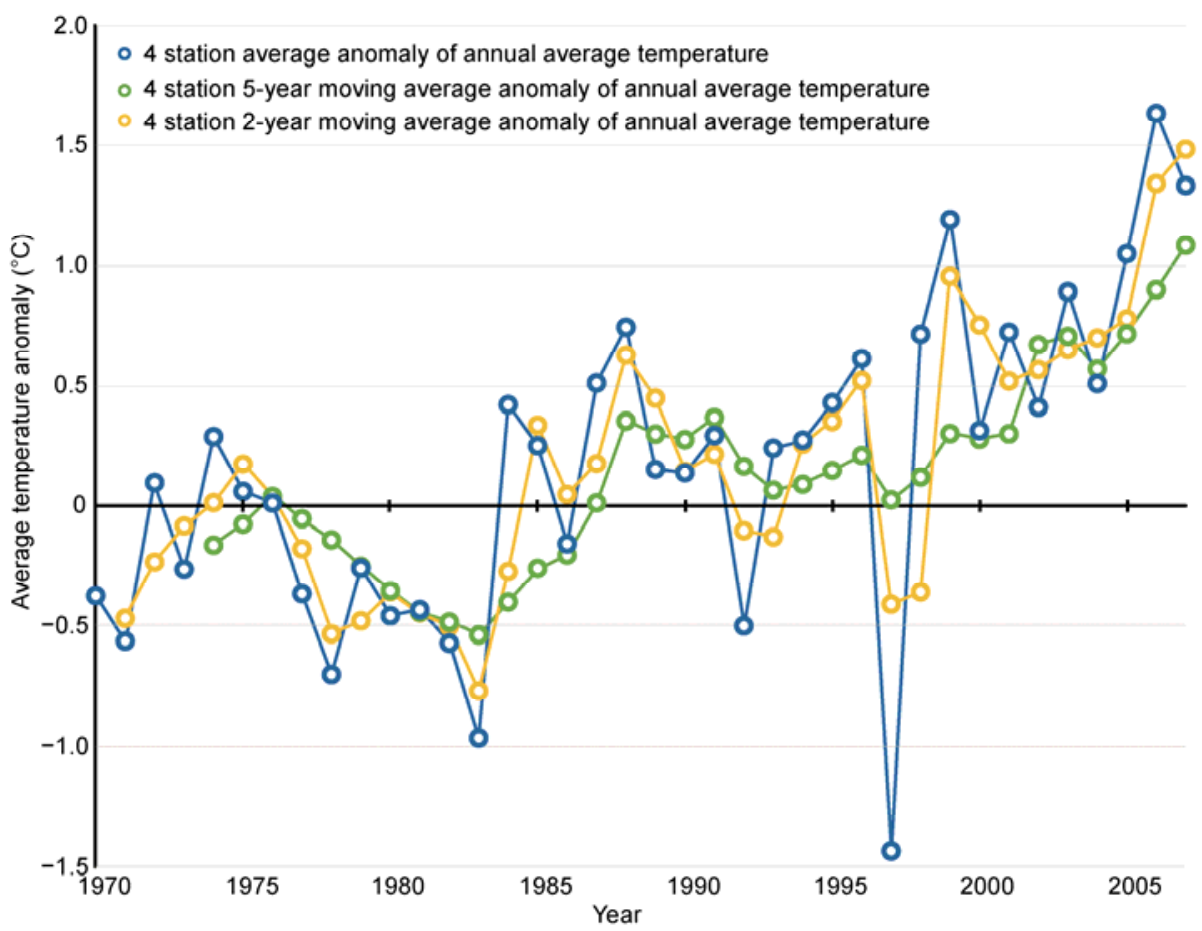

Figure 7 Average temperature anomaly statistics.

Table 3 Correlation coefficients of lake area and meteorological data

\begin{tabular}{lccc}
\hline & Siling Co & Co'e & Bangor Co \\
\hline Five-year moving average annual precipitation & 0.4767 & 0.3907 & 0.8194 \\
Two-year moving average annual precipitation & 0.0133 & 0.4415 & 0.4137 \\
Five-year moving average percentage of annual precipitation anomaly & 0.2159 & 0.3518 & 0.6446 \\
Two-year moving average percentage of annual precipitation anomaly & 0.0060 & 0.3339 & 0.3989 \\
Five-year moving average annual temperature & 0.8844 & 0.0227 & 0.8995 \\
Two-year moving average annual temperature & 0.6950 & 0.0217 & 0.6542 \\
Five-year moving average annual temperature anomaly & 0.9821 & 0.0058 & 0.7233 \\
Two-year moving average annual temperature anomaly & 0.7203 & 0.0070 & 0.5234 \\
\hline
\end{tabular}



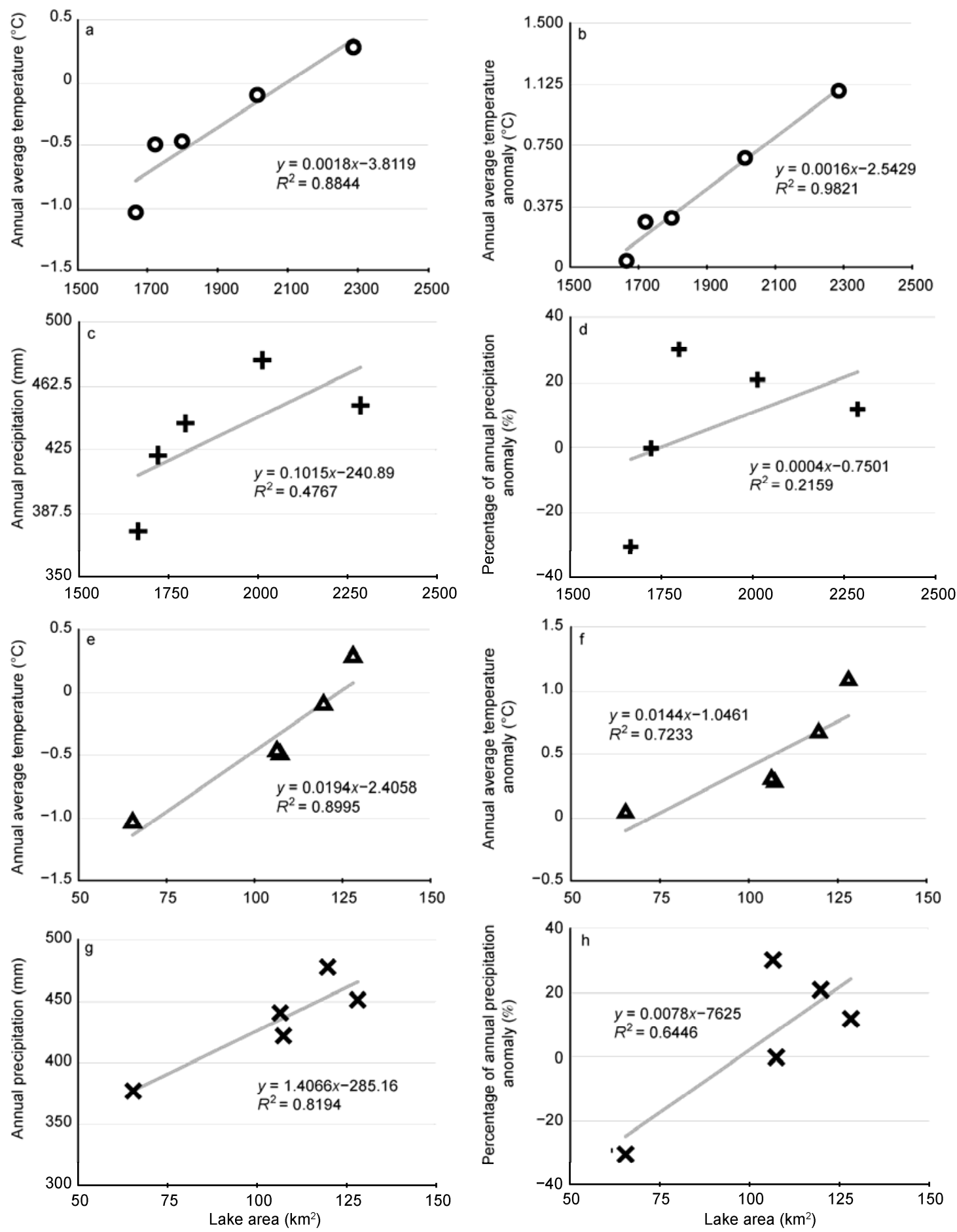

Figure 8 Linear fit of lake area and meteorological data. a, Area of Siling Co/Five-year moving average annual average temperature; b, area of Siling Co/five-year moving average annual average temperature anomaly; c, area of Siling Co/five-year moving average annual precipitation; d, area of Siling $\mathrm{Co} /$ five-year moving average percentage of annual precipitation anomaly; $\mathrm{e}$, area of Bangor Co/five-year moving average annual average temperature; $\mathrm{f}$, area of Bangor Co/five-year moving average annual average temperature anomaly; g, area of Bangor Co/five-year moving average annual precipitation; $\mathrm{h}$, area of Bangor Co/five-year moving average percentage of annual precipitation anomaly.

Siling Co, and the regional long-term precipitation is the secondary factor (Figure 8c,d). According to the research of $\mathrm{Pu}$ [15] and Yao [19], the temperature on the Tibetan Plateau has increased rapidly from the 1980s, and this trend has resulted in accelerated glacial retreat. According to $\mathrm{Lu}$ and
Yao [20,21], the area of Geladaindong Glacier decreased from $899.31 \mathrm{~km}^{2}$ in 1969 to $884.4 \mathrm{~km}^{2}$ in 2000 (a rate of decrease of $1.7 \%$ ). During this time, the main lakes that are supplied by glacial melt water on the Tibetan Plateau (e.g. Nam Co and Siling Co) expanded significantly. According 
to an ice-core $\delta^{18} \mathrm{O}$ survey of Geladaindong Glacier [22], the increasing rate of temperature change from the 1970s has been obviously faster than at other places in the northern hemisphere. The increasing rate of temperature change in the 1990s was about twice that observed in the 1970s. This phenomenon indicated that the trend in annual average temperature increases is accelerating and that high altitude regions are apparently more sensitive to global warming. The study further confirmed "continued warming in Central Eastern Tibet", a view also held by previous researchers $[15,19,20]$. The specific impact of ongoing warming on Siling Co may be accelerated melting of upstream glaciers such as Geladaindong, and increased melt water flow through those rivers into the lake, eventually leading to significant changes in the lake.

Significantly, changes in Bangor Co have been correlated with the long-term changes of precipitation (Table 3, Figure $8 \mathrm{~g}, \mathrm{~h})$. According to the field survey, we found no glacial melt water supply for Bangor Co. Therefore, changes in lake processes in Bangor Co over the past 10 years have been dominated by increases in the annual precipitation. Interestingly, we found that the changes in Bangor Co are also related to long-term temperature changes (Figure 8e,f). One possible explanation is that although both Siling Co and Bangor Co have shown a good correlation between lake area and long-term temperature change, the role of temperature change in these two lakes is not the same. Temperature increases lead to the accelerated melting of glaciers, and the subsequent increase in melt water input directly into the lake. This effect occurs quickly and directly. With regard to Bangor Co, the temperature increases of the 30 years to 2009 have resulted in a decrease in the maximum depth of permafrost in Northern Tibet, at a rate of 0.15-1.9 $\mathrm{cm} / \mathrm{a}$ [10]. Although this melting of permafrost has a limited effect on Siling Co, even a small amount of permafrost melt water could affect Bangor Co because of its shallow lake basin (water depths $<2 \mathrm{~m}$ ) [5]. However, a time lag would occur between the temperature increase and the expansion of the lake. This effect occurs slowly and indirectly, and the topography of the lake basin determines how the change of Bangor Co is related to long-term temperature changes.

Other explanations have been proposed to explain the changes observed in Siling Co. For example, Lu considered that the area expansion of Siling Co, Co'e and Bangor Co is related to the tectonic uplift of the Tibetan Plateau. He proposed that this area subsided relative to the rest of the uplifted plateau [23]. Additionally, Yang proposed that the central part of the Nujiang-Bangong Suture reached maximum deformation under N-S oriented compressive stress. It is very possible that the expansion of Siling Co is therefore the result of neo-tectonic movement in an E-W direction, related to the suture. Consequently, these kinds of stresses shorten the length of Siling Co in the N-S direction, but still result in a larger lake area [3]. However, we believe that because of the limitations of the short time-scale, it is diffi- cult to consider the neo-tectonic effects as the main reason for the increase in lake area and elevation. Besides, as reported elsewhere, there are many inland lakes in the drainage area of Siling Co, such as Wuru Co, Qiagui Co, and Geren Co. Among these many lakes, Siling Co has the lowest catchment area in the region $[3,10,13]$. Moreover, although Bangor Co was connected to Siling Co at the beginning of the Holocene, they are now separated by sandy lake sediments that have better permeability to water. Therefore, an "entangled" relationship exists between them [5]. We believed that this interpretation is contrary to the terrain observed between the two lakes and the actual history of them. According to Zhao, from the 1970s to 1990s, the lake level of Bangor Co had minor fluctuations [5], and the lake level of Siling Co was higher than the lake level of Bangor Co from the 1970s. If there is an "entangled" relationship between the two lakes, according to the terrain and water pressure, the lake level of Bangor Co should continue to rise. However, the fact is the ongoing rise in the lake level of Bangor Co began in the 1980s, and an obvious lake level fluctuation appears in the late 1990s. These observations are all inconsistent with the "entangled" view. In addition, through field investigations, we have found that the lower level sediments around Siling Co are well cemented. Therefore, Siling Co could not possibly connect to Bangor Co through those sediments.

\subsection{Estimates of glacial melt water supply in Siling Co}

The balanced equation for lake level changes could be expressed as

$$
\Delta h=P+R-E \pm \varepsilon,
$$

where $\Delta h$ is variation of lake level in unit time; $P$ is the regional precipitation in unit time; $R$ is the river supplement in unit time $\left(R_{\mathrm{B}}\right.$ : river supplement of Bangor $\left.\mathrm{Co}\right) ; E$ is the regional evaporation in unit time; $\varepsilon$ is the variation caused by the melting of permafrost, groundwater, and water infiltration in unit time [4].

Above all, after 2000 , the change of lake level $\left(\Delta h_{\mathrm{B}}\right)$ of Bangor Co is $0.2 \mathrm{~m}$, and the water supplement of Bangor Co by runoff $\left(R_{\mathrm{B}}\right)$ is negligible. Therefore, we can estimate the lake level as

$$
\Delta h_{\mathrm{B}} \approx P-E \pm \varepsilon \approx 0.2 m .
$$

Because the weather conditions of these three lakes are similar, the contributions of increasing precipitation and declining evaporation to the change in lake level are the same. So, the $(P-E \pm \varepsilon)$ can be offset in the comparison of three lakes. Therefore, the river supplement of Siling Co $\left(R_{\mathrm{S}}\right)$ is

$$
\begin{gathered}
R_{\mathrm{S}}=\Delta h_{\mathrm{S}}-(P-E \pm \varepsilon), \\
R_{\mathrm{S}}=\Delta h_{\mathrm{S}}-\Delta h_{\mathrm{B}}, \\
R_{\mathrm{S}}=8.2 \mathrm{~m}-0.2 \mathrm{~m}=8 \mathrm{~m} .
\end{gathered}
$$

This means that the river supplement made the lake level 
of Siling Co increase by about $8 \mathrm{~m}$. We can get the river supplement to Co'e at about $4.3 \mathrm{~m}$ in the same way. However, because the Alizangbu River intermittently connects the Sling Co and the Co'e, it may also affect the lake level changes of Siling Co and Co'e to some extent. Nevertheless, the clear rise of lake level and the expansion of lake area in Siling Co are definitely related to accelerated glacial melting in the 10 years to 2009 .

\section{Summury}

(1) From 1976 to 2010, the lake level variation process underway in Siling Co can be divided into two stages. From 1976 to 2000 , the lake level steadily rose $4.3 \mathrm{~m} \mathrm{(4530}$ to $4534.3 \mathrm{~m})$; the average growth rate was $0.18 \mathrm{~m} / \mathrm{a}$. From 2000 to 2010, the lake level rapidly increased $8.2 \mathrm{~m} \mathrm{(4534.3}$ to $4542.5 \mathrm{~m}$ ); the average growth rate dramatically rose to $0.82 \mathrm{~m} / \mathrm{a}$. Compared with the rapid increasing progress of Siling Co in the 10 years to 2009, the fluctuation of lake levels in Co'e and Bangor Co were smooth and inconspicuous.

(2) From 1976 to 2009, the lake area of Siling Co experienced a "steady-rapid-steady" expansion process. The lake area of Siling Co has increased by $656.64 \mathrm{~km}^{2}$ in the 34 years to 2009 , with a growth proportion of $39.4 \%$. Since 1999 especially, the lake area of Siling Co has been significantly increased by $549.77 \mathrm{~km}^{2}$, with a growth proportion of $30.6 \%$.

(3) According to the correlation analysis, the rise in regional temperature which has led to the ablation of glaciers, is the main contributor the rise in rapid change in Siling Co in the 10 years to 2009. In fact, the lake level of Siling Co has increased by about $8 \mathrm{~m}$ as a result of the glacier melting directly. The increase of precipitation in the Siling Co drainage area is the secondary factor. The dominant factor for Bangor Co is the increase of precipitation in the long term, whereas the rising temperature becomes the secondary factor.

We are very grateful to the anonymous reviewers and the associate editors who provided useful comments, which significantly improved the clarity and presentation of the results. This work was supported by the Knowledge Innovating Program of Chinese Academy of Sciences (KZCX2-YW-12), the National Basic Research Program of China (2011CB403106) and the National Natural Science Foundation of China (40940018).

1 Shen Y P, Liang H. Global ice melting accelerated would threaten to human environmental safety (in Chinese). J Glaciol Geocryol, 2001, 23: 208-211

2 Oviatt C G. Lake bonneville fluctuations and global climate change.
Geology, 1997, 25: 155-158

3 Yang R H. The dynamic analysis of remote sensing information for monitoring the expansion of the Selincuo lake in Tibet (in Chinese). Remote Sens Land Resour, 2003, 56: 64-67

4 Zhu L P, Xie M P, Wu Y H. Quantitative analysis of lake area variations and the influence factors from 1971 to 2004 in the Nam Co Basin of the Tibetan Plateau. Chin Sci Bull, 2010, 55: 1294-1303

5 Zhao Y Y, Zhao X T, Zheng M P, et al. The denivellation of Bankog Co in the past 50 Years, Tibet (in Chinese). Acta Geol Sin, 2006, 80: 876-884

$6 \mathrm{Wu} \mathrm{Y} \mathrm{H,} \mathrm{Zhu} \mathrm{L} \mathrm{P.} \mathrm{The} \mathrm{response} \mathrm{of} \mathrm{lake-glacier} \mathrm{area} \mathrm{variations} \mathrm{to}$ climate change in Nam Co catchment, central Tibetan Plateau, during 1970-2000. J Geogr Sci, 2008, 18: 177-189

7 Raymo M E, Ruddiman W F. Tectonic forcing of late Cenozoic climate. Nature, 1992, 359: 117-122

8 Kutzbach J E, Guetter P J, Ruddiman W F, et al. Sensitivity of climate to late cenozoic uplift in southern Asia and the American west: Numerical experiments. J Geophys Res, 1989, 94: 18393-18407

9 Li J J. The environmental effects of the uplift of the Qinghai-Xizang plateau. Quat Sci Res, 1991, 10: 479-483

10 Bian D, Bian B, La B, et al. The response of water level of Selin Co to climate change during 1975-2008 (in Chinese). Acta Geol Sin, 2010, 65: 313-319

11 Gasse F, Arnold M, Fontes J C, et al. A 13000-year climate record from western Tibet. Nature, 1991, 353: 472-475

12 Kong P, Na C G, Fink D, et al. Cosmogenic ${ }^{10} \mathrm{Be}$ inferred lake-level changes in Sumxi Co basin, western Tibet. J Asian Earth Sci, 2007, 29: 698-703

13 Bian D, Yang Z G, Li L, et al. The response of lake area change to climate variations in north Tibetan Plateau during last 30 years. Acta Geol Sin, 2006, 61: 510-518

14 Liu D Z. Remote sensing image analysis of the lake-shrinking on the Tibetan Plateau (in Chinese). Remote Sens Land Resour, 1992, 14: $1-6$

15 Pu J C, Yan T D, Wang N L, et al. Fluctuations of the glaciers on the Qinghai-Tibetan Plateau during the past century (in Chinese). J Glaciol Geocryol, 2004, 26: 517-522

16 Guan Z H. The Rivers and the Lakes in Tibet (in Chinese). Beijing: Science Press, 1984

17 Doin M, Twardzik C, Ducret G, et al. Visco-elastic rebound of the lithosphere around the lake Siling Co in Tibet observed by InSAR. In: American Geophysical Union, Fall Meeting 2010, Abstract \#G41B0817,2010

18 Zhang G Q, Xie H J, Zhu M Q, et al. Water level changes of two Tibetan lakes Nam Co and Selin Co from ICESat altimetry data. In: Geoscience and Remote Sensing (IITA-GRS), 2010 Second IITA International Conference, 2010. 463-466

19 Pu J C, Yao T D, Wang N L, et al. Purugangri ice field and its variations since the little ice age of the northern Tibetan Plateau (in Chinese). J Glaciol Geocryol, 2002, 24: 87-92

20 Lu A X, Yao T D, Wang L H, et al. Study on the fluctuations of typical glaciers and lakes in the Tibetan Plateau using remote sensing (in Chinese). J Glaciol Geocryol, 2005, 27: 783-792

21 Lu A, Yao T, Liu S Y, et al. Glacier change in the Geladandong area of the Tibetan Plateau monitored by remote sensing (in Chinese). J Glaciol Geocryol, 2002, 24: 559-562

22 Kang S C, Zhang Y J, Qin D H, et al. Recent temperature increase recorded in an ice core in the source region of Yangtze River in Tibetan Plateau. Chin Sci Bull, 2007, 52: 825-831

23 Lu P, Qu Y G, Li Q W, et al. Shelincuo and Bangorcuo extensional lake basins in the northern part of Tibet and present chasmic activites (in Chinese). Jilin Geol, 2003, 22: 15-19

Open Access This article is distributed under the terms of the Creative Commons Attribution License which permits any use, distribution, and reproduction in any medium, provided the original author(s) and source are credited. 